\title{
Viability of Pollen of Two Fruit Crop Cacti of the Genus Hylocereus Is Affected by Temperature and Duration of Storage
}

\author{
Christiane Metz ${ }^{1}$, Avinoam Nerd ${ }^{2}$, and Yosef Mizrahi', ${ }^{1,2}$ \\ Ben-Gurion University of the Negev, P.O. Box 653, Beer-Sheva 84105, Israel \\ Additional index words. Hylocereus undatus, Hylocereus polyrhizus, dehydration, pollen \\ quality
}

\begin{abstract}
Hylocereus undatus (Haw.) and H.polyrhizus (Weber) are new fruit crops of the Cactaceae. In Israel, flowers of the two species, which are self-incompatible, are hand cross-pollinated. In order to ensure a current supply of compatible pollen and guarantee good yields, we have developed a procedure for long-term storage of pollen. Pollen for storage was collected in the evening or in the morning. Its moisture content ranged between $45 \%$ to $50 \%$ in the evening and between $18 \%$ to $22 \%$ in the morning. Pollen was first dehydrated in a vacuum desiccator until the moisture content was reduced to $5 \%$ to $10 \%$ and then stored at various temperatures $\left(+4,-18,-70,-196{ }^{\circ} \mathrm{C}\right)$ for 3 or 9 months, after which it was used for cross-pollination. Percent fruit set and fruit fresh weight (FW) were affected by the temperature but not the duration of pollen storage; storage at $+4{ }^{\circ} \mathrm{C}$ reduced fruit set, fruit $\mathrm{FW}$, and seed number more than did storage at subfreezing temperatures. The FW of fruits produced by frozen pollen was similar to that produced by fresh pollen in commercial orchards. The rate of seed germination was high $(\approx 90 \%)$ regardless of the temperature during pollen storage.
\end{abstract}

The epiphytic cacti Hylocereus undatus and $H$. polyrhizus are new commercial fruit crops native to tropical America (Nerd and Mizrahi, 1997). The fruit, known in Latin America as pitaya, is a medium-large berry with a scaly peel. Hylocereus undatus is the species most widely cultivated for fruit and is grown extensively in Vietnam, Central America, and southern Mexico. In Guatemala, Nicaragua, and Mexico, Hylocereus orchards are grown in the open, and grower intervention is not required for fruit set (Barbeau, 1990; Reyes-Ramos, 1995). In Israel, shading of orchards is required to protect the plants from the damaging effects of high solar radiation, and hand-pollination is practiced due to the absence of suitable pollinators (Nerd and Mizrahi, 1997; Raveh et al., 1998).

Flowers of the genus Hylocereus are hermaphroditic and nocturnal, staying open only for one night (Nerd and Mizrahi, 1997). Clones of $H$. undatus and $H$. polyrhizus are selfincompatible, but are compatible with clones of the other species (Weiss et al., 1994). Hence, the two species are cultivated together to ensure the availability of pollen for inducing fruit set. However, the flower waves of these

Received for publication 8 Feb. 1999. Accepted for publication 12 Apr. 1999. We thank the Fleischer Foundation and the Israel Ministry of Agriculture for partial support of the research, and Ms. Dorot Imber for editing the manuscript. Work performed in partial fulfillment of the requirements for $\mathrm{PhD}$ thesis of C. Metz. The cost of publishing this paper was defrayed in part by the payment of page charges. Under postal regulations, this paper therefore must be hereby marked advertisement solely to indicate this fact.

${ }^{1}$ Dept. of Life Sciences

${ }^{2}$ The Institutes for Applied Research. species, which occur between May and November, do not coincide exactly, particularly at the beginning and end of the flowering period (Weiss et al., 1994), and in the absence of cross-pollination no fruits are set. This problem may be overcome by the use of stored pollen, which will also be useful in hybridization programs. To date there are no published studies of storage techniques for pollen of Hylocereus or other cacti (Boyle et al., 1995).

Cacti pollen was found to be trinucleate, and in general this characteristic is closely correlated with short storage life (Brewbaker, 1967). Our preliminary studies showed that pollen of $H$. undatus and $H$. polyrhizus, collected in the evening or in the morning, lost its fertility within 1 day of storage at room temperature or after a few days at lower temperatures $\left(+4\right.$ or $\left.-18^{\circ} \mathrm{C}\right)$.

Pollen collected in the morning contained less moisture than that collected in the evening and kept slightly better during storage. Therefore, we assumed that reducing the moisture content prior to storage would improve pollen longevity, as has been reported for several plant species (Connor and Towill, 1993; Hughes and Lee, 1991; Luza and Polito, 1988; Yates et al., 1991).

The main purpose of this work was to develop a method for storing the pollen of $H$. undatus and $H$.polyrhizus and to examine the effect of storage temperature on fruit fresh weight (FW) and seed number.

\section{Materials and Methods}

Plant material. Studies were conducted from 1996 to 1998 on cultivated clones of $H$. undatus (clone B) and H. polyrhizus (clone C) (Weiss et al., 1994) planted in 1992 in a greenhouse located in Beer-Sheva (Northern Negev, Israel) (Nerd and Mizrahi, 1998). Twenty plants of each clone were used both as pollen donors and recipients of stored pollen. Each stored sample comprised pollen grains of several flowers in order to minimize the effects of interfloral variation.

Pollen dehydration. To determine whether dehydration affected pollen viability and to develop a suitable dehydration procedure, the following methodology was used. Fifty-milligram samples of pollen grains were spread in open petri dishes (5.5-cm diameter) and dehydrated over silica gel in a vacuum desiccator $(-50 \mathrm{kPa})$ at room temperature. Pollen weight was determined in four samples of each pollen source at 30-min intervals, until the decrease in weight was negligible. The initial moisture content of pollen collected in the evening or in the morning was determined in samples oven dried for $30 \mathrm{~min}$ at $70^{\circ} \mathrm{C}$. Pollen viability was determined by in vitro germination tests.

In vitro germination of dried pollen. Prior to in vitro germination tests, fresh pollen with low moisture content and stored pollen samples were rehydrated for $3 \mathrm{~h}$ at $25^{\circ} \mathrm{C}$ in a $100 \%$ relative humidity chamber. Rehydration was found to significantly increase germinability when initial moisture content was below $\approx 25 \%$. Germinability of pollen having a higher initial water content was not improved by rehydration. Samples of $5 \mathrm{mg}$ of pollen were spread on glass slides coated with a thin film of a medium consisting of $1 \%(\mathrm{w} / \mathrm{v})$ agarose, $30 \%(\mathrm{w} /$ v) sucrose, $10 \%(\mathrm{w} / \mathrm{v})$ starch, and $100 \mathrm{mg} \cdot \mathrm{L}^{-1}$ each of $\mathrm{H}_{3} \mathrm{BO}_{4}, \mathrm{Ca}\left(\mathrm{NO}_{3}\right) \cdot 4 \mathrm{H}_{2} \mathrm{O}, \mathrm{MgSO}_{4}, \mathrm{KNO}_{3}$, (Weiss et al., 1994). Starch was found to enhance germination and to promote tube growth (data not presented). Slides were placed on wet filter paper in a closed petri dish kept at $25{ }^{\circ} \mathrm{C}$ for $24 \mathrm{~h}$. Germination percentage was determined by microscopic examination of at least 500 randomly selected pollen grains per sample. Grains were scored as germinated when tube length exceeded grain diameter.

Long-term storage. The pollen used for the study was collected in late June and midSeptember (the first and last large flowering flushes, respectively). Prior to storage, pollen was dried in a vacuum desiccator until moisture content was $5 \%$ to $10 \%$ of the initial value. Storage temperatures were $+4{ }^{\circ} \mathrm{C}$ (refrigerator), $-18^{\circ} \mathrm{C}$ and $-70{ }^{\circ} \mathrm{C}$ (freezing chambers), and $-196^{\circ} \mathrm{C}$ (liquid nitrogen container, MVE Cryogenics, New Prague, Minn). Eppendorf test tubes $(0.7 \mathrm{~mL})$ were used for storing pollen in the refrigerator or freezing chambers, while cryotubes $(1.3 \mathrm{~mL})$ were used for storage in liquid nitrogen. Pollination with pollen collected in June was performed 3 months later, while pollen collected in September was tested 9 months later. Pollen was applied without rehydration in the evening with a paintbrush to 15 flowers for each storage treatment. Rehydration of stored pollen was not necessary as the stigma is able to rehydrate the dried pollen grains. To avoid unintentional cross-pollination, stigma lobes of each flower were enclosed in a small textile bag immediately after pollination.

Fruit examination. Fruits were harvested 
when ripe, and percent fruit set was calculated and fruit FW was determined. Seed number and germination were determined for six fruits produced by pollen stored for 9 months. Seeds were washed with tap water to remove mucilage, which depresses germination, and then left to germinate on wet filter paper in closed petri dishes at $25^{\circ} \mathrm{C}$.

\section{Results and Discussion}

Pollen dehydration and in vitro germination. In both species, pollen moisture content was much higher in the evening (45\% to $50 \%$ ) than in the morning ( $18 \%$ to $22 \%$ ). However, after $1 \mathrm{~h}$ of dehydration, pollen of both species reached a moisture content of 5\% to $10 \%$ (Fig. 1).

Germinability of fresh pollen sampled in the morning was as high as that sampled in the evening: (79.2 $\pm 3.8 \%$ for $H$. undatus and 82.8 $\pm 5.6 \%$ for $H$. polyrhizus.). In tests carried out in vitro after 3 months of storage germination did not exceed $11 \%$, with no significant effect of temperature (data not shown). However, pollen that does not germinate well on media suitable for freshly collected pollen is not necessarily nonviable (Polito and Luza, 1988; Rajasekharan et al., 1994; Shivanna and Rangaswamy, 1992) and may produce satisfactory fruit set. Moreover, if the pollen load on the stigma is adequate, a sufficient number of pollen grains will be able to ensure fertilization. However, even if pollen is judged viable by in vitro assay, the capacity of the pollen to set fruit cannot be predicted (Yates and Sparks, 1990).

Long-term storage. Flowers pollinated with dehydrated pollen stored at subfreezing temperatures for 3 or 9 months exhibited 100\% fruit set, but fruit set was only $60 \%$ to $70 \%$ when flowers were pollinated with pollen stored at $4{ }^{\circ} \mathrm{C}$ (data not shown). Generally, for both species, pollen stored at $4{ }^{\circ} \mathrm{C}$ yielded smaller fruit than did pollen stored at subfreezing temperatures. The heaviest fruits of $H$ undatus were produced with pollen stored in liquid nitrogen (Fig. 2). Weight of fruit set by pollen stored at subfreezing temperatures was comparable to that of fruits produced by fresh pollen in commercial orchards $(410 \pm 48 \mathrm{~g}$ for $H$. undatus and $330 \pm 35 \mathrm{~g}$ for $H$. polyrhizus).

Seed number was significantly lower in fruits produced by pollen stored for 9 months at $4{ }^{\circ} \mathrm{C}$ than in those produced by pollen kept at subfreezing temperatures, but seed germination was high $(\approx 90 \%)$ regardless of storage temperature (Table 1). Similar germination percentages and relationships between fruit FW and seed number were observed for fruits of the two species produced by fresh pollen (Weiss et al., 1994).

Although pollen of the Cactaceae is classified as trinucleate and generally loses viability rapidly during storage (Brewbaker, 1967), our results indicate that the storage life of cactus pollen may be prolonged significantly by using the appropriate storage method. The generalization that the storage life of trinucleate pollen is shorter was probably based on a limited number of species.

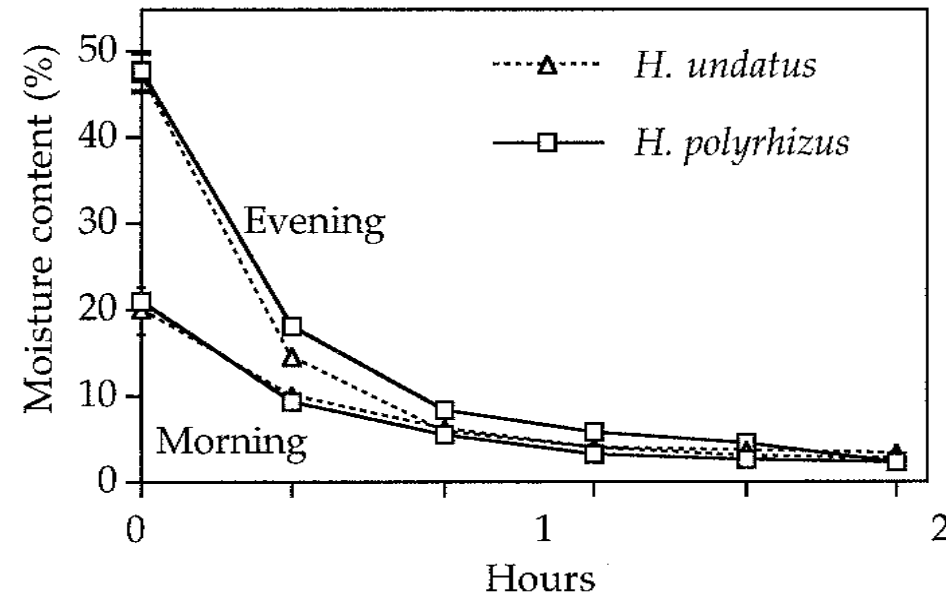

Fig. 1. Time course of dehydration in a vacuum desiccator of Hylocereus undatus and H. polyrhizus pollen collected in the evening (flower opening) or on the following morning (flower closing). Each value is the mean \pm SE for 24 samples collected during June 1997. The SE bars were smaller than the size of the symbols except for data for time zero.

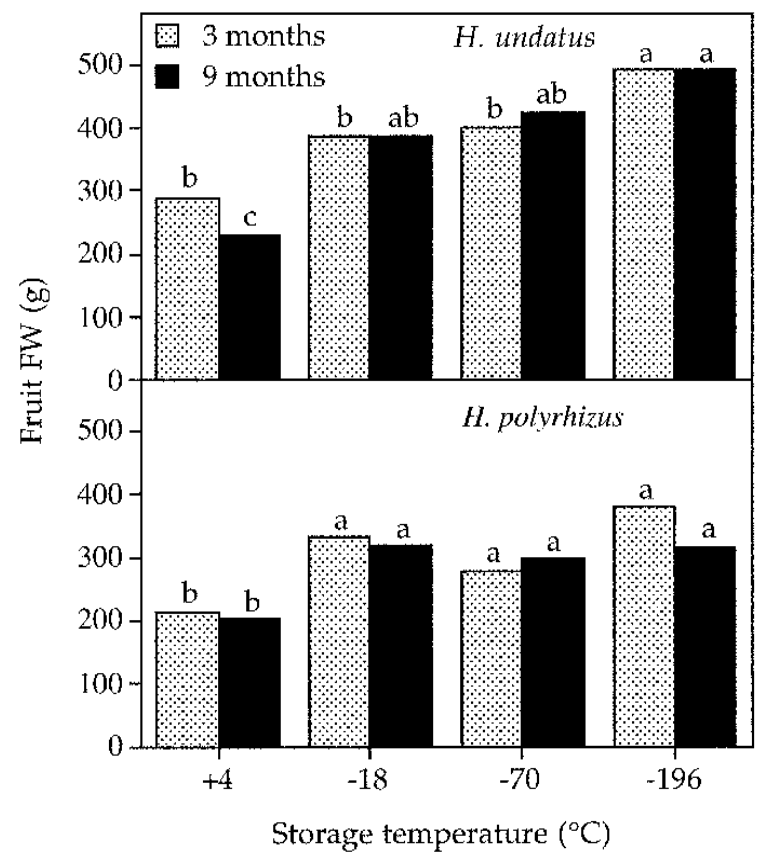

Fig. 2. Fresh weight of fruits of Hylocereus undatus and $H$. polyrhizus following cross-pollination with pollen stored at various temperatures for 3 months (collected in June) or 9 months (collected in September). Mean separation within species by Duncan's multiple range test, $P \leq 0.05$. Fruit FW produced by fresh pollen was $410 \pm 48 \mathrm{~g}$ for $H$. undatus and $330 \pm 35 \mathrm{~g}$ for $H$. polyrhizus. Values are means for 15 fruits per treatment.

Table 1. Seed number per fruit and seed germinability in Hylocereus undatus and H. polyrhizus following pollination with pollen stored for 9 months at various temperatures. Values are means for six fruits. Seed germinability test is based on 400 seeds per treatment and control treatment was performed with fresh pollen.

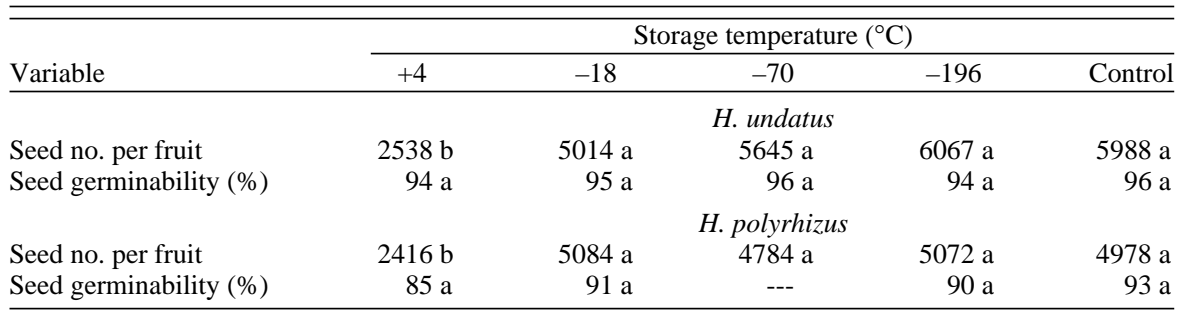

${ }^{\mathrm{z}}$ Mean separation within rows by Duncan's multiple range test at $P \leq 0.05$. 
Pollen with a high initial water content has been reported to be sensitive to stress and short-lived during storage (Georgieva and Kruleva, 1994). However, despite the relatively high initial water content, pollen of Hylocereus tolerated long-term storage after dehydration to $5 \%$ to $10 \%$ moisture content.

In conclusion, Hylocereus pollen may be stored economically for a prolonged period in a household freezer after moisture content has been reduced to $5 \%$ to $10 \%$. For long-term storage, temperatures below $0{ }^{\circ} \mathrm{C}$ should be used in order to ensure satisfactory fruit set. Rehydration of stored pollen prior to pollination is not necessary. Pollen storage could ensure yields in commercial orchards when fresh pollen is unavailable and could facilitate further breeding efforts, since crossings could be made independently of the flowering period.

\section{Literature Cited}

Barbeau, G. 1990. La pitahaya rouge, un nouveau fruit exotique. Fruits 45:141-147.
Boyle, T.H., R. Karle, and S.S. Han. 1995. Pollen germination, pollen tube growth, fruit set, and seed development in Schlumbergera truncata and S. ×buckleyi (Cactaceae). J. Amer. Soc. Hort. Sci. 120:313-317.

Brewbaker, J.L. 1967. The distribution and phylogenetic significance of binucleate and trinucleate pollen grains in the angiosperms. Amer. J. Bot. 54:1069-1083.

Connor, K.F. and L.E. Towill. 1993. Pollen-handling protocol and hydration/dehydration characteristics of pollen for application to long-term storage. Euphytica 68:77-84.

Georgieva, D. and M.M. Kruleva. 1994. Cytochemical investigation of long-term stored maize pollen. Euphytica 72:87-94.

Hughes, H.G. and C.W. Lee. 1991. Low temperature preservation of Clianthus formosus pollen. HortScience 26:1411-1412.

Luza, J.G. and V.S. Polito. 1988. Cryopreservation of English walnut (Juglans regia L.) pollen. Euphytica 37:141-148.

Nerd, A. and Y. Mizrahi. 1997. Reproductive biology of cactus fruit crops. Hort. Rev. 18:321-346.

Nerd, A. and Y. Mizrahi. 1998. Fruit developmen and ripening in yellow pitaya. J. Amer. Soc. Hort. Sci. 123:560-562.
Polito, V.S. and J.G. Luza. 1988. Longevity of pistachio pollen determined by in vitro germination. J. Amer. Soc. Hort. Sci. 113:214-217.

Rajasekharan, P.E., T.M. Rao, T. Janakiram, and S Ganeshan. 1994. Freeze preservation of gladiolus pollen. Euphytica 80:105-109.

Raveh, E., A. Nerd, and Y. Mizrahi. 1998. Responses of two hemiepiphytic fruit crop cacti to different degrees of shade. Scientia Hort. 73:151164.

Reyes-Ramos, V. 1995. El cultivo de las pitahayas y sus perspective de desarrollo en Mexico. ReyesRamos, Tabasco, Mexico. (Booklet.)

Shivanna, K.R. and N.S. Rangaswamy. 1992. Pollen biology. A laboratory manual. SpringerVerlag, Berlin.

Weiss, J., A. Nerd, and Y. Mizrahi. 1994. Flowering behavior and pollination requirements in climbing cacti with fruit crop potential. HortScience 29:1487-1492.

Yates, I.E. and D. Sparks. 1990. Three-year-old pecan pollen retains fertility. J. Amer. Soc. Hort. Sci. 115:359-363.

Yates, I.E., D. Sparks, K. Connor, and L. Towill. 1991. Reducing pollen moisture simplifies longterm storage of pecan pollen. J. Amer. Soc. Hort. Sci. 116:430-434. 